\title{
Integrated Knowledge Management Approach for Academic Improvement in Ubiquitous Computing
}

\author{
K. Kalaiselvi \\ Department of Mathematics \\ Anna University, Chennai, \\ Tamil Nadu, India
}

\author{
G.V. Uma \\ Department of Information Science \& Engineering, \\ Anna University, \\ Chennai, Tamil Nadu, India
}

\begin{abstract}
The paper describes incorporation of Knowledge Management with the Ubiquitous Computing Environment. The development of wireless communication and technologies paved the way for the Ubiquitous Computing in Educational domain. In the Ubiquitous Computing Environment, knowledge can be shared as collaborative learning among the learners. Sharing comprises entire knowledge management life cycle. The paper mainly concentrates on the design \& implementation of how knowledge can be gained and transferred among learners. Further, it describes the role of K-Transfer which can be imparted among the tutor and the students.
\end{abstract}

Keywords: Collaborative learning, K-Transfer, Knowledge Management, learners, Ubiquitous Computing

\section{INTRODUCTION}

The rapid and accelerating growth in the development and application in the field of wireless and mobile technology influence the evolution of new mode of education. Today's world makes Education more empower using Information and communication technology. Education is the continuous process for improving the knowledge of a person throughout life time. Knowledge management plays a vital role and proven concept in many areas of computer science. Knowledge management plays important role in higher education. Knowledge management application helps to improve the teaching and learning with help of ubiquitous computing technology.

The main goal of Knowledge management systems is to provide the learners with the right information at the right time. During past decade, organizations understand the importance of knowledge and the role of knowledge can be used for the overall improvement of the organization $[8,9,10]$. Knowledge plays a specific role for an individual/group of users with in a specific domain of system. Sharing of knowledge helps to improve the skills of a learners as well as organizations.

Ubiquitous Computing is a user-centric which helps the learners to share their knowledge. The major work of this proposed Paper is to provide a systematic approach based on the suggested components of the knowledge management and designed how ktransfer can be taken place in the collaborative learning.

Collaborative learning is a term used in the variety of educational approaches involving joint intellectual effort by learner or learners \& tutors / subject matter experts together. In collaborative learning activities vary widely but mostly center on student's exploration/ application of learning course material, not simply teacher's presentation / explication of it. It is not typical teacher-centered / Lecture-centered in college class rooms. In collaborative learning approach, it considers tutor should consider themselves as less expert transmitters of knowledge to learners, and more as expert designers of intellectual experiences for learners. In this type of learning it stimulates both the learners as well as tutors/subject matter experts.

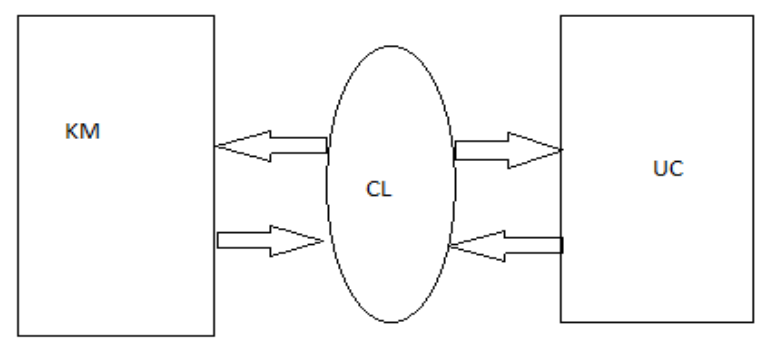

Figure 1. Integration of KM with Ubiquitous Computing

$$
\begin{aligned}
& \text { KM - Knowledge Management } \\
& \text { UC }- \text { Ubiquitous Computing } \\
& \mathrm{CL}-\text { Collaborative learning }
\end{aligned}
$$

The Figure1 shows how the incorporation of Knowledge management with ubiquitous computing through collaborative learning exists among the learners. Learners adopt the KM life cycle to upgrade the knowledge with the help of ubiquitous computing. Knowledge can be shared between knowledge seeker and knowledge provider. Knowledge seeker is the learner who wants to upgrade their knowledge and knowledge provider is the tutor/subject matter expert who prepares the learning content with the support of ubiquitous computing technology.

This paper explores the incorporation of Knowledge management with ubiquitous computing. Organization of this paper is structured as follows: the section 2 describes about the literature survey of the evolution of ubiquitous computing with knowledge management in education domain. Section 3 vividly explains about the knowledge management life cycle. Section 4 provides the working procedure of ubiquitous computing and Section 5 explains the role of knowledge management with ubiquitous computing. Further it details about how K-transfer exists among the learners with the ubiquitous computing. Finally, section 6 gives the conclusion and future work of this paper.

\section{RELATED WORK}

From an academic knowledge perspective, the learning community should start at the individual level, create 
departmental knowledge, create domains of knowledge across departments that share academic interests or disciplines, create institutional knowledge networks and networks with other institutions and corporations (Galbreath, 2000).

In Educational perspective, the Knowledge management should provide information about how to link people, processes, and technologies and discuss how organizations can promote policies and practices that help people to share and manage knowledge (Petrides \& Nodine, 2003). There are two types of knowledge involved in higher education settings: academic knowledge and organizational knowledge. Academic knowledge is the primary purpose of universities and colleges. Organizational knowledge refers to knowledge of the overall business of an institution: its strength and weaknesses, the markets it serves, and the factors critical to organizational success (Coukos-Semmel, 2003). It is believed that knowledge management can be used to support educational administration, which in turn supports teaching and learning (Petrides \& Guiney, 2002).

\section{KNOWLEDGE MANAGEMENT (KM) LIFE CYCLE}

Knowledge management life cycle consists of six components viz. $\mathrm{K}$-create, $\mathrm{K}$-store, $\mathrm{K}$-share, $\mathrm{K}$-transfer, $\mathrm{K}$-reasoning and $\mathrm{K}$ reuse. In Figure 2 depicts the life cycle of Knowledge Management.

K-create - learning content are prepared by the tutor/Subject matter experts. The learning content stored in different levels for different learner category. The different levels are low level, middle level and high level.

K- Store - The prepared learning content are stored in the database by the administrator. Administrator issues permission for accessing learning content by the learners. Administrator takes control for issuing authorized user (tutor/Subject matter experts) for modification of content if necessary. It consists of repository of information in the K-base.

K-share - Learners retrieve the learning content and acquire knowledge out of it. Different course/learning materials are accessed by different learners. Learners with different ideas learn the content with the help of collaborative learning.

$\mathrm{K}$ - Transfer - After the successful completion of collaborative learning, knowledge acquired by the learners are transferred from one learner to other.

$\mathrm{K}$ - Reasoning - After knowledge acquired by the learners, the knowledge gained by the learners are verified by the tutor/ subject matter experts thru assessment of the learnt content.

K- Reuse - The updated / modified information authenticated by the tutor/SME the learning content are updated in the database.

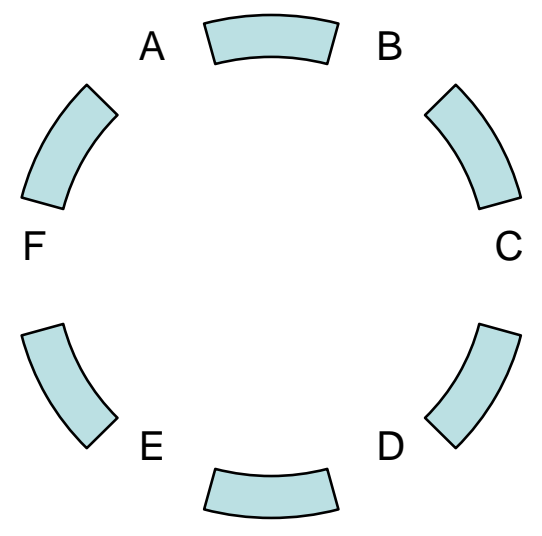

Figure 2. Knowledge Management Life Cycle
A - K -Create
B - K-Store
C - K-Share
D - K - Transfer
E - K-Reasoning
F - K-Reuse

\section{WORKING OF UBIQUITOUS COMPUTING}

In ubiquitous computing environment, it enables the learners to learn the information by accessing via with the different devices namely mobile/PDA/Personal Computer. Learning content are prepared by the subject matter experts/ tutor stored in the database with the help of database administrator.

Using wireless technology $\mathrm{WiFi}$ and blue tooth, the information transferred to the different learners. Bluetooth can take short range of distance to transfer the information to the learners. WiFi is best to cover a maximum range to transfer the information to the learners.

Device includes the memory, which enables the learners to easily access the information. The learning content can be learnt by the authorized learners by registering the student's profile. Learners allowed to select their preferred content with their different levels of category.

\section{ROLE OF KM WITH UC}

$\mathrm{K}$-Transfer life cycle consists of three Components namely $\mathrm{K}$ Identification, K- Mitigation and K-Quantification. KMonitoring is a Knowledge flow between learners. KIdentification is a process of identifying learners group categorized using the levels of category chosen by the learners. $\mathrm{K}$ - Monitoring is a knowledge flow between learners / learners to tutor/ Subject Matter Expert; it is continuous process of learning. K-Mitigation is process which makes a mind/brain to acquire enough knowledge and achieved knowledge is stored as a back-up in the brain of the learners. K-Quantification is a process of discovering a new information from the learned content through the process of collaborative learning. 


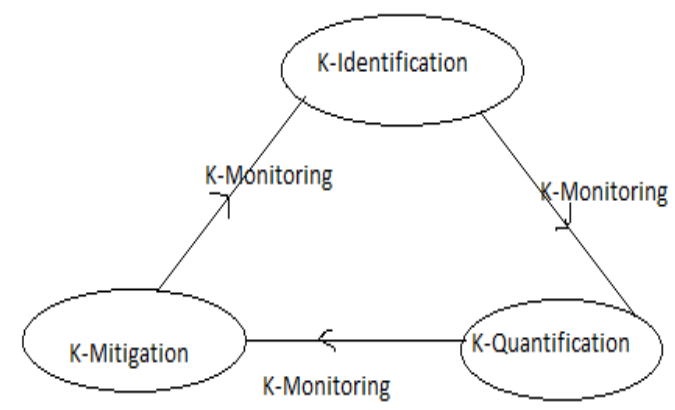

Figure 3. Knowledge Transfer Life Cycle

K-transfer methods are used in ubiquitous computing environment in order to gain the knowledge. K-transfer methods used are Peer Assist, Action Review and Retrospect.

In ubiquitous computing environment, the components included are microprocessor with memory, content module, wireless technology and the devices mobile/PDA/Personal Computer. Knowledge sharing and transfer between learners can be done through the collaborative learning using ubiquitous computing environment.

\section{CONCLUSION}

This paper explored the importance of knowledge sharing and knowledge transfer in the ubiquitous computing environment. Learners can learn the learning content anywhere, anytime. It integrates the Knowledge management effectively as that of organization with the ubiquitous computing environment for the higher education. It also paved way for the improvement of quality in higher education.

\section{REFERENCES}

[1] Jong Hyuk Park, Jianhua Ma, Laurence T.Yang,Anind K.Dey, " Special Issue on Intelligent Systems and Services for Ubiquitous Computing" , Pervasive ubiquitous Computing (2009) 13: 445-447.

[2] Kidwell, Jillinda J., Vander Linde, Karen M., and Sandra L. Johnson (2001), “ Applying Corporate Knowledge
Management Practices in Higher Education”. EDUCAUSE Leadership Series \#3 San Francisco: Jossey -Bass. Pp.1-24.

[3] Luyili, yanlinzheng, Hiroaki ogata, yoneo yano, "A framework of U-learning environment", Department of Information science and intelligent systems 2004 IEEE.

[4] Milam, John H.,Jr..” Knowledge Management for Higher Education", ERIC Digest, http://www.ericdigests.org/20031/higher.htm.

[5] Muhammed Rafi, Young-Koo Lee and Sungyoung Lee, “ Knowledge Management Framework for Ubiquitous Systems", 2006 IEEE.

[6] Shi-Kuo Chang, Timothy K.Shihl (2007), “ Ubiqutious Computing Technologies in Education", International Journal of Distance Education Technologies volume 5, Issue 4.

[7] Smith, B., and J.MacGregor, "What is Collaborative Learning?”, in Goodsell, A., M. Mahler, V.Tinto, B.L.Smith, and J.MacGreger,(Eds), Collaborative Learning: A sourcebook for Higher Education.

[8] Thorn, Christopher A.(2001) "Knowledge Management for Educational Information Systems - What is the State of the Field?" Educational Policy Analysis Archives(9):47 2001. Available online at:http://epaa.asu.edu/epaa/v9n47/.

[9] Vicki Jones and Jun H.Jo , “ Ubiquitous learning environment: An adaptive teaching system using ubiqutious technology", Proceedings of the $21^{\text {st }}$ ASCILITE Conference( pp. 468 -474. Perth, 5-8 December. http://www.ascilitie.org.au/conferences/perth04/procs/jones .html.

[10] Weiser, Mark. "The computer for the Twenty-First Centruy". Scientific American September 1991. pp. 94104.

[11] Yaying Mary cho yeh,YungTa, "The implementation of Knowledge Managements in Taiwan's Higher Education, Information of Technology and Commerce, Taiwan, Journal of college Teaching and learning, 2005.

[12] Yishang, HongcHiShi \& Su-Shing Chen, "An intelligent Distributed environment for active learning", ACM Journal of educational resources in computing, Summer 2001. 